\title{
Recursos Humanos na Implantação das Ações Integradas de Saúde no Município de Ribeirão. Preto - Visão da Equipe de Enfermagem
}

\author{
Silvana Martins Mishima* \\ Maria Cecília Puntel de Almeida* \\ lara Carneiro Ungari** \\ Eliete Maria Silva*
}

O presente trabalho procurou identificar as possiveis alterações quantitativas sofridas no contingente de recursos humanos, especificamente do pessoal de enfermagem, existente no município de Ribeirâo Preto, no periodo compreendido entre 1984 e 1987

(Correspondente à implantação das AIS). Concluiu-se que, efetivamente, em Ribeirão Preto é possivel afirmar que as AIS tiveram um papel fundamental no sentido da mudança estrutural dos serviços de saúde vinculados ao subsetor público, especialmente na esfera municipal, bem como na absorção de pessoal de saúde em geral e de enfermagem em particular.

Unitermos: Ações Integradas de Saúde, Sistema Único de Saúde, recursos humanos em saúde, pessoal de enfermagem.

\section{INTRODUÇÃO}

No bojo de uma proposta racionalizadora elabor ada no sentido de responder à crise fin anceira e política e reorientar a assistência à saúde no âmbito da Previdência Social, buscando a universalização dos serviços de saúde, a ampliaçāo da oferta destes nas áreas de maior déficit, as Ações Integradas de Saúde constituíram-se, a partir de sua criação em 1983, no principal instrumento estratégico de coordenação das instituições públicas do setor.

Enquanto estratégia de reorientação, o "Programa das Açöes Integradas de Saúde, parte integrante do Plano do Conasp, encerrou em seus princípios e diretrizes a histórica aspiração do setor saúde por mudanças efetivas. No momento atual, porém, o que nasceu como um programa institucional do Inamps passou a

* Enfermeira Docente da Escola de Enfermagem de Ribeirão Preto - USP.

* Enfermeira da Secretaria de Saúde do Municipio de Ribeirão Preto. ser assumido pelos demais Ministérios e Secretarias de Saúde dos Estados, como eixo comum sobre o qual deve-se caminhar, daqui para frente, no sentido de real in tegração" (1).

$\mathrm{Na}$ direção desța in tegraçāo, buscando a construção de um Sistema Único de Saúde, no primeiro semestre de 1987 inicia-se o processo de implantação dos

Cadernos de Saúde Pública, RJ, 6(1): 40-49. jan/mar, 1990 
Sistemas Unificados Descentralizados de Saúde a nível de vários estados da Federação, tendo como um dos pontos essenciais a "municipalização da rede básica de saúde".

Entremeada a esta discussão, surge a questão dos recursos humanos, de reconhecida importância na produção de serviços de saúde, sendo apontada entre os problemas principais a serem resolvidos para superação das limitações e deficiências do setor (6).

Levando-se em consideraçāo a impcrtârcia da questão dos recursos humanos frente às Açōes Integradas de Saúde, enquanto estratégia para a construção do Sistema Unificado Descentralizado de Saúde (SUDS), tendo como base o Sistema Único de Saúde, no presente trabalho procurar-se-á identificar as possíveis alteraçōes quantitativas sofridas no contingente de recursos humanos existente no município de Ribeirão Preto, com ênfase nos recursos de enfermagem, no período de implantação das Açōes Integradas de Saúde $(1984$ - 1987).

Não discutiremos as mudanças qualitativas, apesar de entendermos sua importância, pois, neste caso, teríamos de utilizar outro referencial metodológico, que extrapolaria a questão específica de recursos humanos, contemplando a própria avaliação qualitativa dos serviços.

\section{METODOLOGIA}

Este trabalho foi basicamente realizado em duas etapas distintas, porém complementares.

$\mathrm{Na}$ primeira etapa, foi efetuado o levantamento dos recursos médico-sanitários no município de Ribeirão Preto, durante o período de outubro a novembro de 1984, onde foram identificados os recursos médicosanitários existentes no município, com ênfase nos recursos humanos presentes a nível municipal, estadual e federal (para maior conhecimento dos dados e do estudo realizado, ver referência 4 ).

A importância desta data inicial (1984) é que corresponde à época de assinatura do convênio das A ções Integradas de Saúde para o município de Ribeirão Preto, tendo como partes convenentes a Secretaria Municipal de Saúde de Ribeirão Preto, a Secretaria de Estado da Saúde de São Paulo e o Inamps.

Neste segundo momento, durante os meses de outubro e novembro de 1987, foi realizado o levantamento dos recursos humanos em saúde, no universo das instituições de saúde do município de Ribeirão Preto, mediante aplicação de um formulário ligeiramente alterado em relação àquele utilizado no levantamento de 1984, englobando a identificação da instituição, o tipo de atendimento oferecido, a disponibilidade 
de recursos especializados e os recursos humanos disponíveis, incluindo aí todo o pessoal de saúde.

O formulário aplicado foi baseado naquele utilizado pelo IBGE (Assistência Médico-Sanitária), no qual foram feitas alterações para melhor caracterizar as instituiçóes e os recursos humanos, de acordo com os objetivos deste trabalho.

O formulário foi preenchido, em sua maioria,pelos pesquisadores ou pelo entrevistador, com dados fomecidos majoritariamente pelo diretor clínico ou administrativo da instituição; em alguns casos a parte específica de Recursos Humanos foi preenchida pelo responsável do setor de Recursos Humanos da instituição. Cabe ressaltar que em treze por cento (13\%), devido a trâmites burocráticos, o formulário foi preenchido pela própria instituição, sendo revisado pelo pesquisador no momento da entrega.

Os dados obtidos através dos formulários aplicados em 1987 foram comparados com os dados do levantamento realizado em 1984. Buscou-se portanto, através da compáração dos dados, verificar e tentar explicar as possíveis alteraçōes sofridas no contingente de recursos humanos, especialmente os de enfermagem, presentes no município de Ribeirão Preto, no subsetor público.

\section{APRESENTAÇÃO E DISCUSS ÃO DOS DADOS}

Tido na região, bem como no Estadn, romo grande centro formador e prestador de serviços, o município de Ribeirão Preto pode ser considerado um centro médico-sanitário de expressivo vulto, dispondo de ampla rede de sérviços de Saúde. Através da Tabela I, pode-se observar que o município, em 1984, contava no subsetor público com 7 centros de saúde, 5 ambulatórios e 14 postos de saúde, 1 hospital e 2 hospitais e ambulatórios.

Das 22 unidades municipais identificadas em $1987,16(72,7 \%)$ foram classificadas como Centros de Saúde (embora no âmbito municipal recebam a denominação de Unidades Básicas de Saúde), por se constituírem em unidades médico-sanitárias que apresentam certa complexidade na prestação de assistência médica; $1(4,5 \%)$ como Ambulatório (sendo que este presta atendimento apenas aos servidores municipais); $2(9,1 \%)$ como Postos de Saúde e $3(13,6 \%)$ como Pronto-Socorros, prestando assistência em situaçōes de urgência. Neste período houve a fusão de uma unidade municipal e uma estadual que atuavam na mesma área geográfica. Esta unidade, para efeito deste trabalho, foi classificada como um Centro de Saúde Municipal. 
Tabela I - Estabeleciment os de saúde da rede públi ca, segundo classificação e tipo de institui ção em 1984 e 1987. Ribeirão Preto - 1987.

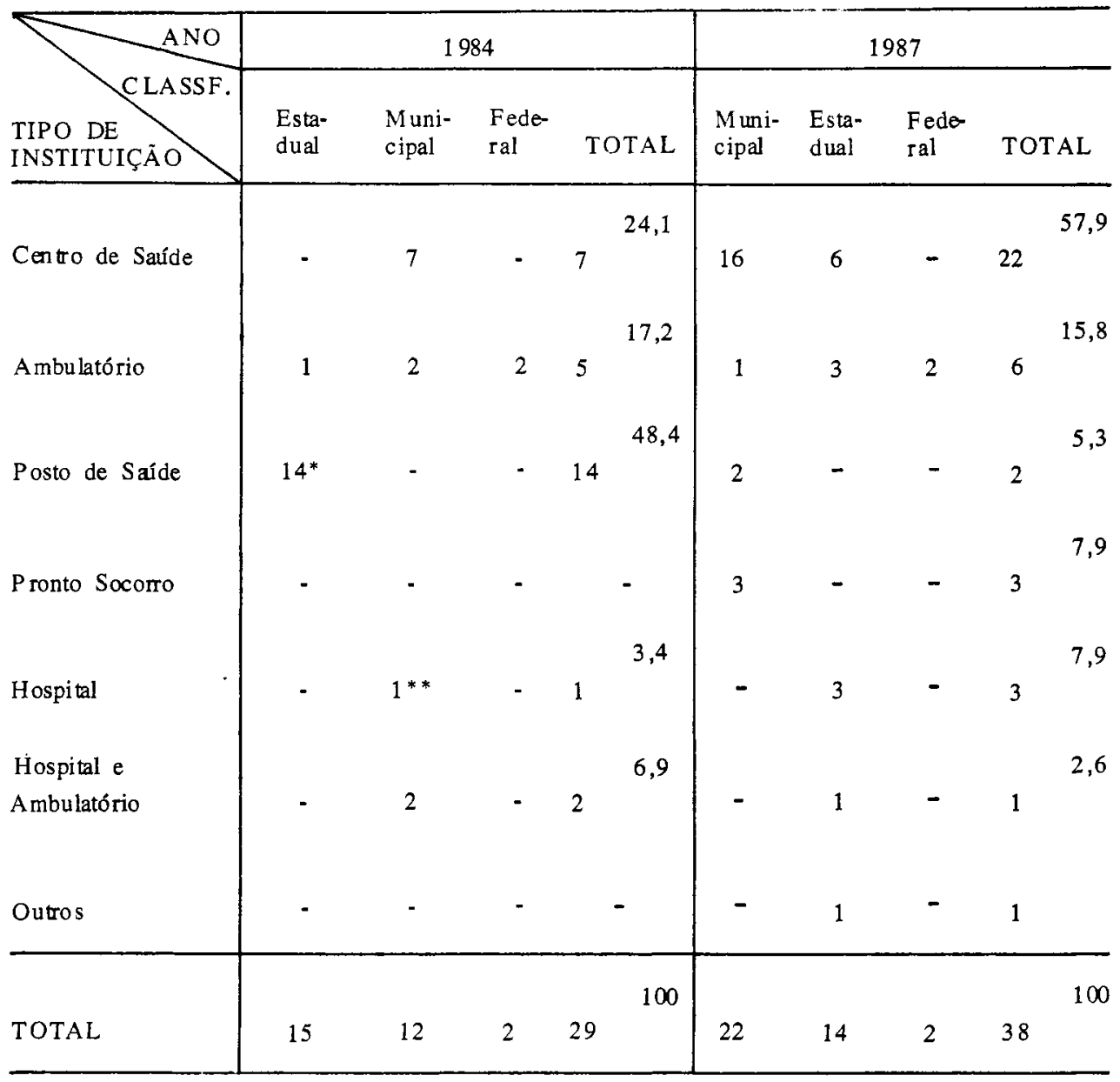

* Inchuídos al 3 Pronto-Socorrns Municipais

** Referente à Unidade de Emergênc ín do Hospital das Clínicas

Os Postos de Saúde (ou Postos Médicos, definidos como instituições que mantêm serviços de pronto atendimento) representavam, em $1984,48,4 \%$ das instituições do setor, realizando apenas atendimento de urgência sem a preocupação com o seguimento rotineiro do cliente, em um sistema organizado de informaçōes (4).

Calernos de Saíde Pública, RJ, 6(1): 40-49. jan/mar, 1990 
A grande maioria das unidades municipais $(72,7 \%)$, que se constitui nas Unidades Básicas de Saúde, da rede básica de atendimento em 1987, contava com um sistema organizado de informações e seguimento rotineiro da clientela atendida. Nẫo é possível se afirmar que houve uma alteração qualitativa dos serviços, pois tal afirmação extrapola os limites deste estudo. Contudo, pode-se afirmar que houve a implementação e ampliação da infra-estrutura, possibilitando um atendimento de melhor qualidade.

Ainda na Tabela I, evidencia-se que a rede municipal apresentou, no período de 1984 - 1987, um crescimento significativo $(46,6 \%)$, passando de 15 unidades em 1984 para 22 em 1987.

É importante assinalar que, no subsetor público, a rede municipal ainda é dominante, sendo que, em 1984, representava $51,7 \%$ das instituições públicas, e, em 1987 , passou a $57,9 \%$.

O subsetor público estadual basicamente nāo apresentou alteraçốes ern sua rede de instituições prestadoras de serviços, uma vez que, com a unificação, a ampliação da rede municipal de saúde cobriu as possíveis defasagens numéricas, percebidas como prioritários no período.

Durante o período 1984 - 1987, houve a instalação, no município, de um Ambulatório do IAMSP (Instituto de Assistência Médica do Servidor Público) e a fusão de uma unidade sanitária estadual com uma municipal, já mencionada acima. No estudo de 1987 , foram ainda incluídos um serviço de Vigilância Epidemiológica e uma unidade hospitalar, que atua em regime de semi-internação, ligada ao Hospital das Clínicas de Ribeirão Preto, ambos estaduais (não inclú́dos no estudo de 1984). Neste período também, o Ambulatório Regional de Saúde Mental foi desmembrado do Hospital Psiquiátrico.

O subsetor público, como um todo, apresentou um crescimento da ordem de $31 \%$, sendo que este crescimento deveu-se, basicamente, ao crescimento registrado no setor municipal. Ainda é possível afirmar que, neste período de implantação das AIS, houve uma modificação real da estrutura dos serviços de saúde do município.

Enfocando a questao dos recursos humanos, podese observar pela Tabela II 0 crescimento verificado no subsetor público no período, sendo que o grupo dos trabalhadores com formação de nível elementar foi o que apresentou maior crescimento $(36,5 \%)$, seguido pelós profissionais de nível universitário $(30,7 \%)$.

Cadernos de Saúde Pública, RJ, 6(1): 40-49. jan/mar, 1990 
Tabela II - Crescimento da força de trabalho em saúde segundo categoria profissional no período, 1984 - 1987, Ribeirẵo Preto - 1978.

\begin{tabular}{l|c|c|c}
\hline $\begin{array}{l}\text { Nível de } \\
\text { Escolaridade }\end{array}$ & 1984 & 1987 & $\%$ \\
\hline Nível Universitário & $775^{*}$ & 1013 & 30,7 \\
Nivel Médio & 756 & 873 & 15,5 \\
Nível Elementar & 712 & 1122 & 36,5 \\
\hline TOTAL & 2243 & 3008 & 34,1 \\
\hline
\end{tabular}

* Excluídos 340 médicas residentes do Hospital das Clínicas.

A proposta de extensão de cobertura da população, veiculada nos discursos oficiais, define que $o$ profissional mais qualificado deve atuar, em situaçóes mais complexas, de forma a racionalizar tempo, trabalho e recursos. As afirmações de Girardi (2) sobre - crescimento dos empregos em saúde, são que as explicaçóes para este devem ser buscadas "nas especificidades que marcam as relaçōes entre estes serviços, o Estado e a estrutura produtiva na formação social brasileira". Coloca, inicialmente, que um dos fatores seria que os serviços de saúde são sustentados direta ou indiretamente pelos Estados; e em seguida pelo fato do "setor funcionar como uma espécie de 'tampão' para demandas sociais reprimidas, agravadas em conseqüência do modelo econômico, deve contribuir também para o crescimento do volume de empregos no setor, especialmente nos movimentos de crise econômica, quando a demanda por estes serviços aumenta" (5). Ambas colocaçöes possibilitam um entendimento deste crescimento.

É importante, contudo, que se ressalte que a proposta da Atenção Primária à Saúde, embutida na estratégia das AIS, nâo implica a baixa qualidade da assistência prestada, mas sim num serviço que ofereça resolução ao problema apresentado pelo cliente, constituindo-se na porta de entrada para um sistema de saúde hierarquizado. É possível que, gradativamente, venha a ser necessário um número maior de pessoal qualificado, a fim de prestar uma assistência integral e que apresente resolutividade à clientela atendida. 
Possivelmente a preocupação de extensão de cobertura, expressa na proposta das AIS, foi o fator que mais contundentemente con triubuiu para o crescimento dos trabalhadores de nível elementar.

Especificamente falando dos trabalhadores de enfermagem e tomando-se os dados obtidos em 1984 , constata-se que, no período compreendido entre 1984 e 1987, houve um crescimento do pessoal de enfermagem no setor saúde como um todo (público e privado) da ordem de $35 \%$, sendo que o público foi o que apresentou o maior crescimento $(45,7 \%)$.

A Tabela III permite uma melhor visualização de como se deu este crescimento, no período 1984 - 1987, especificamente no subsetor público, podendo-se observar que a categoria que apresentou maior crescimento foi a dos atendentes $(51,4 \%)$, seguida pela categoria dos auxiliares de enfermagem $(48,9 \%)$.

Aqui é importante frisar que, no período, foram instituídas no município alteraçōes importantes no que tange a qualificação do pessoal contratado para as instituições públicas. Exemplo dessa situação é a Secretaria Municipal da Saúde do Município de Ribeirão Preto que, a partir de 1986 , em relação ao pessoal de nível médio elementar, passou a contratar para sua rede de postos de atendimento apenas auxiliares de enfermagem. Outro exemplo diz respeito aos serviços ligados à Universidade de São Paulo (Unidades do Centro de Saúde Escola) que, a partir de 1987, em função da Lei do Exercício Profissional, passaram a contratar pessoal qualificado (técnico e auxiliar de enfermagem) para seu quadro funcional .

Verifica-se, ainda na Tabela III, o crescimento observado na categoria dos enfermeiros, na rede ambulatorial pública (Centros de Saúde e Ambulatórios) de cerca de $210 \%$. Embora tenha havido um crescimento tão expressivo desta categoria, é fundamental que se ressalte que sua participação no conjunto de profissionais de saúde e na própria enfermagem é ainda muito reduzida.

Da mesma forma que a categoria dos enfermeiros, as demais categorias de enfermagem também apresentam um crescimento muito intenso na rede ambulatorial, sendo que o técnico de enfermagem, antes inexistente na rede ambulatorial, surge representando 4,9\% do pessoal de enfermagem aí alocado; o auxiliar de enfermagem apresenta um crescimento da ordem de $58,3 \%$, enquanto que o atendente, de $96,7 \%$. Estes dados vêm reforçar afirmações de que vem ocorrendo, principalmente no subsetor público, especificamente nos estabelecimentos sem in ternação, uma "ambulatorização dos empregos em enfermagem".(3) 


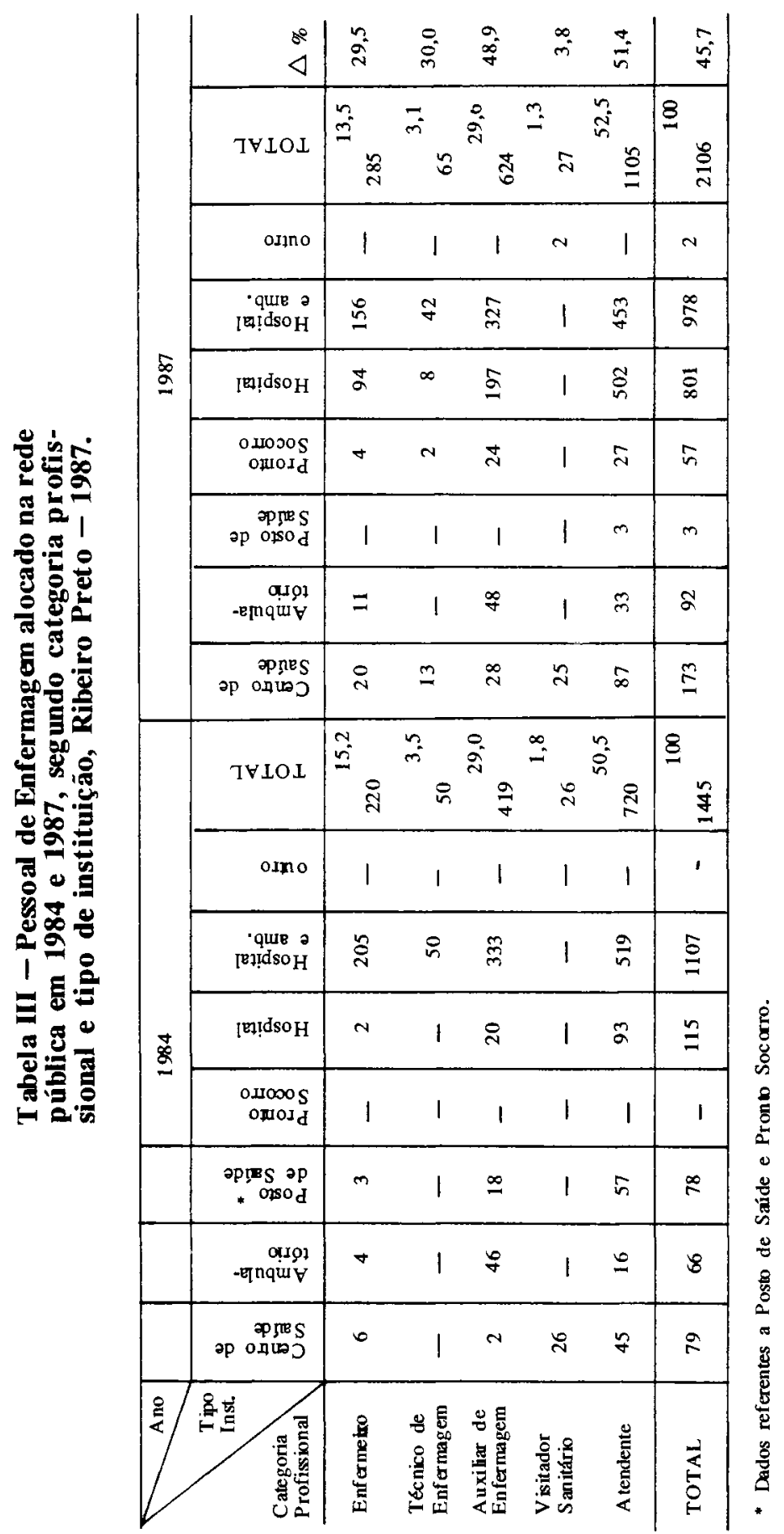


Tal tendência, acredita-se estar associada à estratégia de implantação das AIS (3), o que pode ser evidenciado claramente no município de Ribeirão Preto.

Chama atenção, ainda, para o fato de que,embora tenha havido um crescimen to significativo, quantitativamente, do pessoal de enfermagem como um todo no subsetor público, e de que as categorias com qualificação específica (no caso do técnico e auxiliar de enfermagem) tenham sido introduzidas na força de trabalho em en fermagem no referido subsetor, năo houve, contudo, uma alteração marcante no perfil de distribuição das diferentes categorias de enfermagem.

É importante frisar, que apesar da restrição existente quanto à utilização de pessoal de nível elementar, sem formação específica, expressa no artigo 23 da Lei $n: 7498$, que dispōe sobre a regulamentação do exercício da enfermagem, permanece, pelo menos a nível do município de Ribeirã̃o Preto, a intensa utilização de atendentes, tanto a nível do subsetor público como privado. No período compreendido entre 1984 e 1987 houve um crescimento do número de atendentes na rede de serviços de saúde da ordem de $35,8 \%$, sendo que o crescimento no subsetor público é da ordem de $51,4 \%$ e ainda mais marcante na área hospitalar em contrapartida ao subsetor privado, da ordem de $14,6 \%$.

\section{CONSIDERAÇÕES FINAIS}

Toda discussão em tomo da constituição de um Sistema Único de Saúde reforça a necessidade de uma política de recursos humanos séria e competente, contemplando os aspectos relativos à força de trabalho, como também aqueles relativos à preparação do pessoal de saúde.

Cabe, contudo, frisar que o estabelecimento de medidas legais que garantam a melhoria das condiçōes de trabalho e de preparação do trabalhador de saúde pode não al terar o quadro hoje estampado de desvinculação e descompromisso de grande parte destes quanto ao seu papel na reorganizaçăo dos serviços e na prestação de assistência à saúde.

O engajamento efetivo dos profissionais de saúde, incluindo aí todas as categorias de trabalhadores, traduzido pela utilização máxima do potencial do trabalhador, implica que este esteja motivado para assumir e recriar a estrutura organizacional que ora vem se delineando.

Estrutura esta caracterizada pelo oferecimento de uma assistência integral e resolutiva, dentro de uma rede única de serviços regionalizada e hierarquizada, onde se faz necessária a humanização do atendi- 
mento à clientela e a percepção por parte da sociedade da saúde como direito.

Consideramos que no processo de concretização do Sistema Único de Saúde acontece uma mudança, a nível de recursos humanos, com tendência a elevar a concentração de pessoal mais bem qualificado, de forma a viabilizar a necessária resolutividade da rede básica de atendimento.

É possível afirmar que, no município de Ribeirão Preto, as AIS tiveram um papel fundamental na mudança estrutural dos serviços vinculados ao subsetor público na esfera municipal, bem como na absorção de pessoal de saúde em geral, e de enfermagem em específico.

This paper sought to identify the possible quantitative changes in human resources in the governmental health sector, specifically in the nursing staff of the municipality of Ribeirão Preto (SP) during the implementation period of the Health Integrated Actions (AIS), 1984 to 1987.

It is possible to affirm that the AIS influenced structural changes in governmental health services, especially in the area of nursing human resources in the municipality of Ribeirão Preto (SP).

\section{REFERÊNCIAS BIBLIOGRÁFICAS}

1. Conferéncia Nacional de Saúde, 8: - Anais, Brasília, 1986. Brasília: Centro de Documentaçâo do Minsstério da Saúde, 1987. 430p.

2. GIRARDI, S. N. - O papel do "emprego" em saúde no Brasil. Conf. Nacional de Recursos Humanos em Saíde, out/1986 (mimeo).

3. MÉDICI, A. C. \& PAIM, G. R. - Estudo sobre Recursos Humanos para Saúde e dinâmica da força de trabalho em Enfermagem no Brasil na década de 70. (Informe preliminar/RJ, 1987 mimeo).

4. MISHIMA, S. M.; SIlVA, E. M.; AlMEIDA, M. C. P. - Recursos Médico-Sanitários Munić́pio de Ribeiño Preto, 1984. Rev. Medicina 21 (1 e 2); 23-42, jan/jun, 1988.

5. NOGUEIRA, R. P. - Dinámica do Mercado de Trabalho em Saúde no Brasil. 1979 - 1983, Brasília. OPAS, 1986.

6. "Saúde em questâo - sanitaristas apontam os problemas de saúde". Saúde em Debate. SP, n: 5, 1977.

7. VIA NNA, S. M. - Saúde: Descentralizaçăo e Desburocratizaçāo. Brasília D.F., setembro, 1986 (mimeo). 